\title{
Trasplante de membrana amniótica para el tratamiento de queratitis ulcerativa recurrente por virus herpes simple
}

Drozhzhyna Galina ${ }^{1}$, Sereda Kateryna ${ }^{2}$, Vit Valeriy ${ }^{3}$, Molchanuk Nataliya ${ }^{4}$

\section{RESUMEN}

La queratitis por herpes simple es una de las causas más importantes de ceguera por infección corneal. El virus permanece latente en el huésped humano después de la infección primaria y puede ser reactivado por muchos factores, como traumatismos, estrés, exposición al sol, procesos que cursen con fiebre asociada, procedimientos quirúrgicos, entre otros. Una vez activado, se traslada a través del nervio trigémino hacia la córnea y causa la infección recurrente, la cual produce cicatrización corneal.

Clínicamente, la membrana amniótica usada como sustituto de la membrana basal ha sido aplicada satisfactoriamente para el manejo de defectos epiteliales persistentes con o sin ulceración. Además, se ha descrito que el trasplante de membrana amniótica de múltiples capas es útil para el tratamiento de úlceras corneales profundas, descemetoceles y perforaciones corneales pequeñas.

El presente reporte describe un caso de queratitis por herpes simple tratado con membrana amniótica con el que se obtuvo una agudeza visual buena y ausencia de queratitis recurrente durante dos años.

Palabras clave: membrana amniótica, queratitis por virus herpes simple, úlcera corneal, descemetocele.

\section{Amniotic membrane transplantation for the treatment of recurrent ulcerative keratitis due to herpes simplex virus}

\begin{abstract}
Herpes simplex keratitis is one of the leading causes of infectious corneal blindness in the world. It remains latent in the human host after the primary infection and can be reactivated by many factors. When activated, it travels along the trigeminal nerve to the cornea, and causes recurrent infection which leads to corneal scarring.

Clinically, preserved AM used as a basement membrane substitute has been applied successfully for the management of persistent epithelial defects with and without ulcerations. Furthermore, multilayered AMT has been described to be useful for the treatment of deep corneal ulcers, descemetoceles, and small corneal perforations.

This report describes a case of herpes simplex keratitis treated by amniotic membrane transplantation that resulted in high visual acuity and the absence of keratitis recurrent during two years.
\end{abstract}

Key words. amniotic membrane, HSV keratitis, corneal ulcer, descemetocele.

1. Head of the corneal Department.

2. Physician Opthalmologyst.

3. Eye Pathology Department Head.

4. Senior Researcher of Electronic Microscopy Laboratory. 


\section{INTRODUCCIÓN}

La queratitis por virus herpes simple (VHS) es la causa más común de ceguera corneal en países desarrollados. Ha sido estimado que un tercio de la población mundial tiene infección recurrente y es considerada como un problema de salud pública mundial ${ }^{(1)}$. La incidencia global anual (porcentaje de casos nuevos) de queratitis por herpes es aproximadamente 1,5 millones, incluyendo $40 \mathrm{mil}$ nuevos casos de severa discapacidad visual monocular o ceguera ${ }^{(2)}$.

La membrana amniótica, o amnios (la capa más interna de la placenta), consiste en una membrana gruesa y una matriz de estroma avascular. Los datos clínicos experimentales indican que la membrana amniótica facilita la proliferación y diferenciación de las células epiteliales, mantiene el fenotipo epitelial original, promueve la diferenciación de las células caliciformes, y reduce la cicatrización, vascularización e inflamación ${ }^{(3-8)}$. Cuando la membrana amniótica es usada como injerto o como parche, puede promover la curación de úlceras corneales persistentes de diferentes causas, incluyendo queratopatía neurotrópica. Existe el soporte clínico de que el proceso de curación en la queratitis estromal necrotizante por herpes puede ser promovida por el trasplante de membrana amniótica (TMA) $)^{(9,10)}$.

\section{CASO CLÍNICO}

Un paciente de 27 años de edad, sexo masculino, con antecedente de queratitis por VHS fue admitido en el departamento de córnea del Filatov Institute of eye diseases and tissue therapy NAMS of Ukraine con un cuadro de dolor en el ojo izquierdo de dos semanas de duración, fotofobia, y disminución de la visión el día 02 de abril de 2013.

La primera vez que se realizó el diagnóstico de queratitis herpética del ojo izquierdo fue el año 1990, cuando el paciente tenía cuatro años de edad. Desde 1990 al 2011 no se observó recurrencia alguna. Desde el 2011 hasta el 2013 se observaron recurrencias de la queratitis herpética de dos a tres veces por año.

En el examen clínico, la agudeza visual mejor corregida fue de $1,0(20 / 20)$ en el ojo derecho y de $0,02(20 / 800)$ en el ojo izquierdo. El examen con lámpara de hendidura mostró inyección conjuntival y una úlcera corneal geográfica en la zona óptica de 2,5 $\mathrm{mm}$ por $2,5 \mathrm{~mm}$, la cual teñía a la fluoresceína y presentaba una pérdida del $90 \%$ del espesor corneal en el centro de la úlcera (descemetocele). La cámara anterior estaba profunda y sin inflamación, el cristalino era transparente.

Se hizo el diagnóstico de queratitis recurrente ulcerativa por VHS. El paciente fue tratado tópicamente con cloranfenicol y clorhexidina 0,02\% seis veces al día, fenilefrina dos veces al día y valaciclovir $500 \mathrm{mg}$ dos veces al día.

Buscando prevenir una perforación corneal, el 5 de abril de 2013, bajo anestesia general, se realizó un TMA como injerto, con el lado estromal hacia abajo, se colocó tres capas para llenar el lecho de la úlcera, fijándolas con suturas interrumpidas. Se usó membrana amniótica criopreservada a $-196^{\circ} \mathrm{C}$, la cual mantenía sus células epiteliales y estromales viables después del descongelamiento. Al final del tratamiento el 19 de abril del 2013, la agudeza visual mejor corregida fue de 1,0 en el ojo derecho y de 0,01 en el izquierdo. El examen con lámpara de hendidura mostró: conjuntiva normal, lente de contacto blando terapéutico sobre la superficie corneal, y la membrana amniótica segura rodeada de córnea transparente. La cámara anterior estaba profunda, sin actividad, y el cristalino trasparente.

Después del TMA no se presentó recurrencia de queratitis por HVS por dos años. El examen con lámpara de hendidura mostró una opacidad corneal no densa que no teñía a la fluoresceína, la córnea circundante permanecía clara y había una marcada vascularización en el cuadrante temporal inferior de la córnea (Vis OS =0,03).

El 15 de enero del 2015 el paciente se quejó de dolor ocular, disminución de la visión, epífora en el ojo izquierdo y refirió una historia de stress. En el examen clínico, la mejor agudeza visual del paciente era de 1,0 en el ojo derecho y 0,01 en el izquierdo. El examen con lámpara de hendidura mostró inyección conjuntival, úlcera corneal en la zona óptica de 2,5 $\mathrm{mm}$ por $3,0 \mathrm{~mm}$, la cual teñía a la fluoresceína, y la presencia de un descemetocele central. La córnea circundante estaba infiltrada con un edema profuso estromal. La cámara anterior era profunda y tranquila, y el cristalino se mantenía transparente. Se realizó el diagnóstico de queratitis ulcerativa recurrente por VHS.

El 23 de enero del 2015, con el paciente bajo anestesia general, se realizó una queratoplastia lamelar de diámetro $7,00 \mathrm{~mm}$ con propósito 
Trasplante de membrana amniótica para el tratamiento de queratitis ulcerativa recurrente por virus herpes simple

terapéutico. El periodo posoperatorio fue sin incidentes. Al final de tratamiento, el 18 de febrero del 2015, la mejor agudeza visual corregida fue de 1,0 en el ojo derecho y de 0,5 en el izquierdo. El examen con lámpara de hendidura mostró conjuntiva normal, la capa de injerto transparente y fijado con una sutura continua de nylon 10-0. El teñido a la fluoresceína fue negativo. La córnea debajo del injerto no presentaba una opacidad muy intensa. La cámara anterior era profunda, sin reacción inflamatoria y el cristalino estaba claro.

La última visita del paciente fue el 24 de junio del 2015, cuando bajo anestesia local, se le removió la sutura continua del injerto en el ojo izquierdo. El examen con lámpara de hendidura mostró conjuntiva normal, el injerto lamelar trasparente con teñido negativo a la fluoresceína y una opacidad no densa bajo el injerto. La cámara anterior era profunda y tranquila, y el cristalino estaba transparente. La agudeza visual mejor corregida fue de 1,0 en el ojo derecho y $0,3(20 / 60)$ en el izquierdo.

En los especímenes de tejido corneal obtenidos en el intraoperatorio se observó distribución irregular de queratocitos y las placas de colágeno, ambos en parcial estado de degeneración (Figura 1, 2, 5). El estroma estaba cubierto con varios espesores de epitelio estratificado con signos de degeneración vacuolar (Figura 3). Sobre la superficie del epitelio se encontró una tira homogénea que no teñía, que representaba posiblemente los remanentes de membrana amniótica (Figura 4, 5).

Figura 1. Microscopía electrónica que muestra la ultraestructura del estroma corneal. Distribución irregular de las placas de colágeno (x 2500)

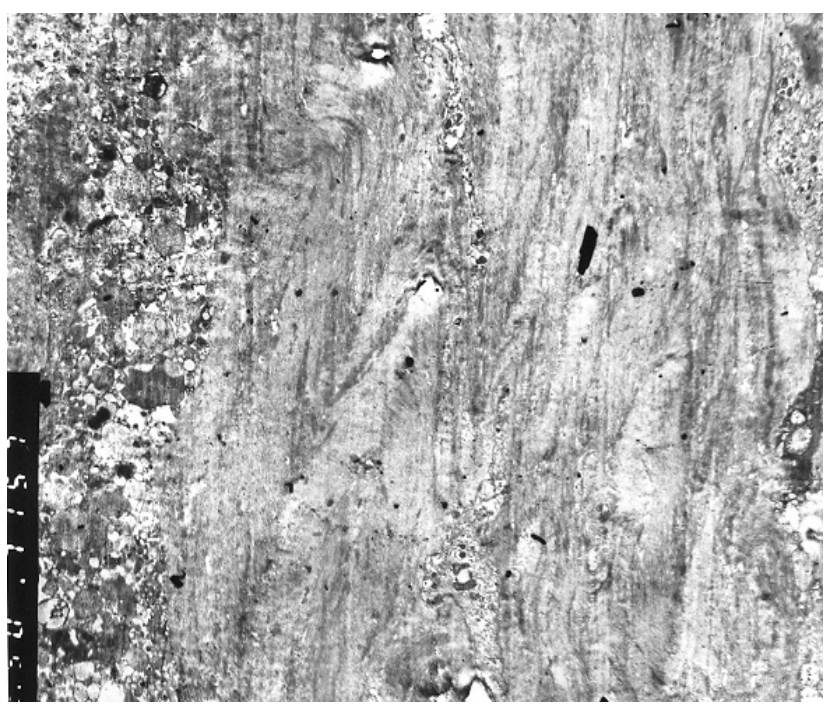

Figura 2. Microscopía electrónica que muestra la ultraestructura del estroma corneal. Degeneración vacuolar de queratocitos (x 6000)

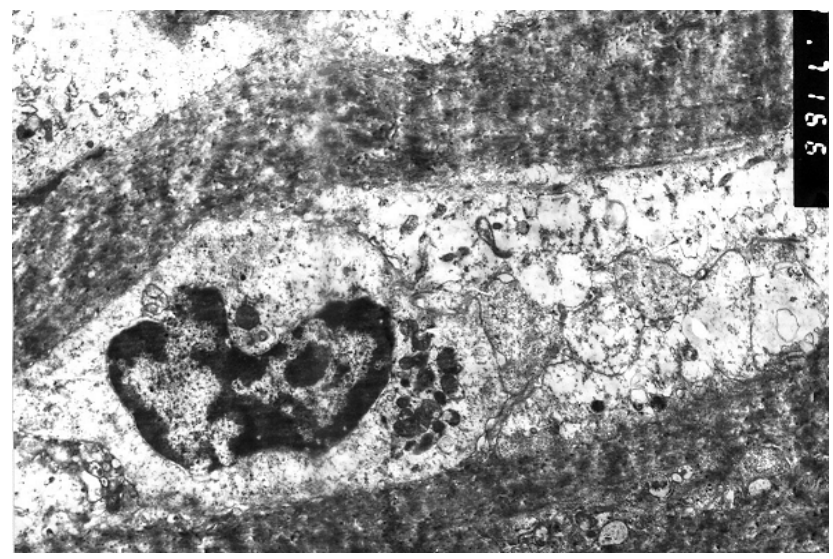

Figura 3. Microscopía electrónica que muestra la ultraestructura del estroma corneal. Degeneración vacuolar de las células epiteliales (x 3000)

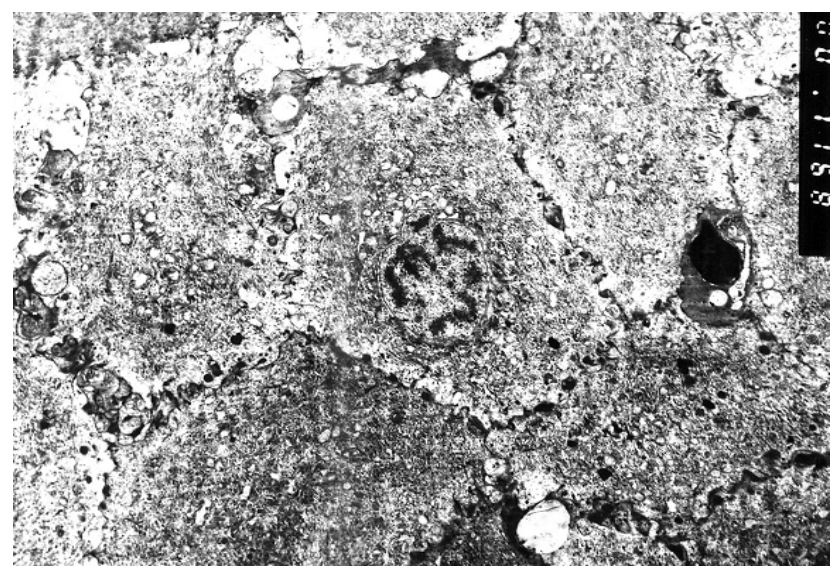

Figura 4. Microscopía electrónica que muestra la ultraestructura del estroma corneal. Remanentes de membrana amniótica parcialmente lisada $(x 4000)$

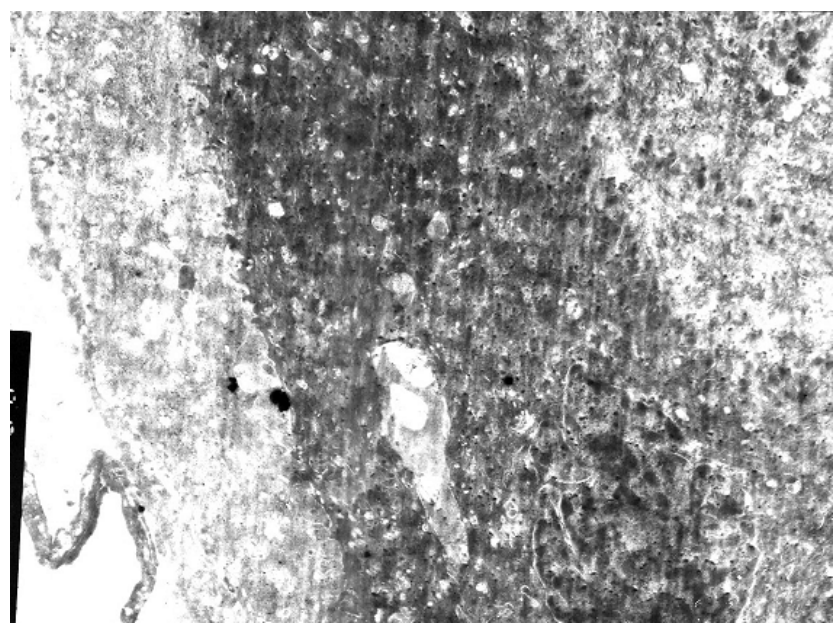




\section{DISCUSIÓN}

El VHS es un virus ADN bicatenario que causa enfermedad después del contacto directo con la piel o con secreciones contaminadas con virus provenientes de las membranas mucosas de un huésped infectado. Una vez en el tejido, el virus se difunde desde el sitio de la infección inicial a los cuerpos celulares de las neuronas. Donde puede quedar en estado inactivo por años hasta que ocurra una reactivación ${ }^{(11)}$.

Se ha reportado que el TMA es un procedimiento quirúrgico efectivo para la reconstrucción de la superficie ocular y para reducir la inflamación corneal ${ }^{(9,10,12,13,14)}$. Los datos clínicos y morfológicos obtenidos en el presente reporte apoyan la idea que el TMA modifica significantemente el curso de la queratitis estromal necrotizante inducida por HVS. Este procedimiento estuvo asociado con supresión de la inflamación, rápida epitelización, reducción de la necrosis estromal e inhibición de la vascularización.

Nosotros observamos que la inflamación estromal se resolvió completamente después del TMA. El lente de contacto blando sobre la membrana amniótica se mantuvo sobre la superficie corneal por cuarenta días. Después que la membrana se disolvió, la epitelización ya estaba completa y no se observaron signos clínicos de inflamación ni vascularización.

Figura 5. Microscopía óptica. Sección del área central de la córnea del paciente que muestra el epitelio y el estroma. Coloración azul de toluidina ( $x$ 40)

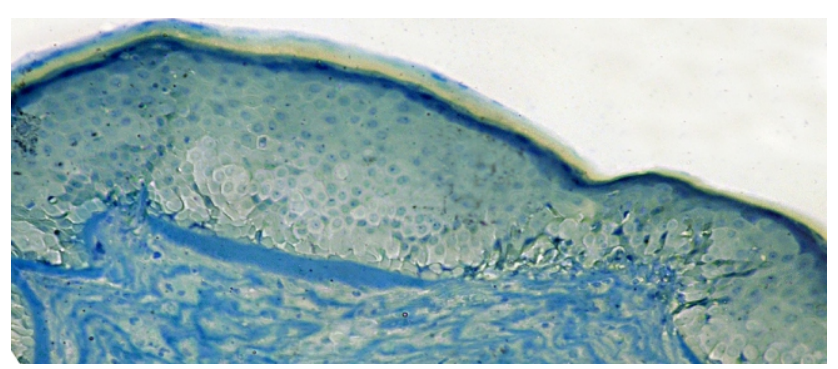

En conclusión, la presencia de epitelización completa, ausencia de infiltración linfocíticahistiocítica y no vascularización muestra que la membrana amniótica posee propiedades para una rápida epitelización e inhibición de la vascularización e inflamación. Gracias al TMA, no se observaron recurrencias de la queratitis herpética durante dos años.

Agradecimiento: Al Dr. Lincoln Lavado Landeo, por la traducción del presente artículo científico.

\section{REFERENCIAS BIBLIOGRÁFICAS}

1. Yanoff M, Duker JS. Ophthalmology. Mosby Elsevier.2009; pp. 279-288.

2. Farooq AV. Shukla D. Herpes simplex epithelial and stromal keratitis: an epidemiologic update. Surv Ophthalmol. 2012; 57 (5): 448-462.

3. Azuara-Blanco A, Pillai CT, Dua HS. Amniotic membrane transplantation for ocular surface reconstruction. $\mathrm{Br} \mathrm{J}$ Ophthalmol. 1999;83:399-402.

4. Cho BJ, Djalilian AR, Obritsch WF, Matteson DM, Chan CC, Holland EJ. Conjunctival epithelial cells cultured on human amniotic membrane fail to transdifferentiate into corneal epithelial-type cells. Cornea. 1999;18:216-224.

5. Meller D, Tseng SC. Conjunctival epithelial cell differentiation on amniotic membrane. Invest Ophthalmol Vis Sci. 1999;40:878-886.

6. Shimazaki J, Yang HY, Tsubota K. Amniotic membrane transplantation for ocular surface reconstruction in patients with chemical and thermal burns. Ophthalmology. 1997;104:2068-2076.

7. Tseng SCG, Prabhasawat P, Lee SH. Amniotic membrane transplantation for conjunctival surface reconstruction. Am J Ophthalmol. 1997; 124:765-774.

8. Tseng SC, Li DQ, Ma X. Suppression of transforming growth factor-beta isoforms, TGF-beta receptor type II, and myofibroblast differentiation in cultured human corneal and limbal fibroblasts by amniotic membrane matrix. J Cell Physiol. 1999;179:325-335.

9. Kruse FE, Rohrschneider K, Voelcker HE. Multilayer amniotic membrane transplantation for reconstruction of deep corneal ulcers. Ophthalmology. 1999;106:1504-1510.

10. Lee S, Tseng SCG. Amniotic membrane transplantation for persistent epithelial defects with ulceration. Am J Ophthalmol. 1997;123:303-312.

11. AAO Basic and Clinical Science Course, External Disease and Cornea, 2010-2011.

12. Kim J, Tseng SC. Transplantation of preserved human amniotic membrane for surface reconstruction in severely damaged rabbit corneas. Cornea. 1995; 14:473-484.

13. Prabhasawat P, Tseng SC. Impression cytology study of epithelial phenotype of ocular surface reconstructed by preserved human amniotic membrane. Arch Ophthalmol. 1997;115:1360-1367.

14. Tsubota K, Satake Y, Ohyama M, Toda I, Takano Y, Ono M,et al. Surgical reconstruction of the ocular surface in advanced ocular cicatricial pemphigoid and Stevens-Johnson syndrome. Am J Ophthalmol. 1996;122:38.

Fuentes de financiamiento

Este artículo ha sido financiado por los autores.

\section{Conflictos de interés}

Los autores declaran no presentar ningún conflicto de interés.

\section{Correspondencia:}

Kateryna Sereda

Dirección: Ukraine, Odessa, 65039, Srednefontanskaya street 19B, kv.223.

Teléfono: 352300

Correo electrónico: evsereda08@gmail.com 